Article

\title{
Light Emission Properties of a Cross-Conjugated Fluorene Polymer: Demonstration of Its Use in Electro-Luminescence and Lasing Devices
}

\author{
Sergio Romero-Servin ${ }^{1, \dagger}$, Luis-Abraham Lozano-Hernández ${ }^{1, \dagger}{ }^{\dagger}$ José-Luis Maldonado ${ }^{1, *}$, \\ Ramón Carriles ${ }^{1, *}$, Gabriel Ramos-Ortíz ${ }^{1, *}$, Enrique Pérez-Gutiérrez ${ }^{1}$, Ullrich Scherf ${ }^{2}$ and \\ Mikhail G. Zolotukhin ${ }^{3}$ \\ 1 Centro de Investigaciones en Óptica A. P. 1-948, 37150 León Guanajuato, Mexico; sromero@cio.mx (S.R.-S.); \\ luis_abraham90@hotmail.com (L.-A.L.-H.); eperez@cio.mx (E.P.-G.) \\ 2 Macromolecular Chemistry Group, Wuppertal University, Gauss-Str. 20, D-42097 Wuppertal, Germany; \\ scherf@uni-wupertal.de \\ 3 Instituto de Investigaciones en Materiales, Universidad Nacional Autónoma de México, A. P. 70-360, \\ 04510 México D. F., Mexico; zolotukhin@iim.unam.mx \\ * Correspondence: jlmr@cio.mx (J.-L.M.); ramon@cio.mx (R.C.); garamoso@cio.mx (G.R.-O.); \\ Tel.: +52-477-441-4200 (R.C.) \\ $\dagger$ These authors contributed equally to this work.
}

Academic Editor: Do-Hoon Hwang

Received: 23 December 2015; Accepted: 1 February 2016; Published: 5 February 2016

\begin{abstract}
Light emission properties of a fluorene cross-conjugated polymer (PF-1) based on the monomer 4,7-bis[2-(9,9-dimethyl)fluorenyl] benzo[1,2,5]thiadiazole are reported. This polymer exhibits solubility at high concentrations, good processability into thin solid films of good quality and a broad emission band with a fluorescence quantum yield of approximately 1 . Based on these features, in this paper we implemented the use of PF-1 as an active layer in polymer light-emitting diodes (PLEDs) and as a laser gain medium in solution. To get insight on the conducting properties of PF-1, two different electron injectors, poly [(9,9-bis $\left(3^{\prime}-(N, N\right.$-dimethylamino $)$ propyl)-2,7-fluorene)-alt-2,7-(9,9-dioctylfluorene)] (PFN) and lithium fluoride (LiF), were used in a simple PLED architecture. PLEDs with the PFN film were found to exhibit better performance with a maximum luminous efficiency of $40 \mathrm{~cd} / \mathrm{A}$, a turn-on voltage $\left(V_{\text {on }}\right)$ of approximately $4.5 \mathrm{~V}$ and a luminance maximum of $878 \mathrm{~cd} / \mathrm{m}^{2}$ at $5.5 \mathrm{~V}$, with a current density of $20 \mathrm{~A} / \mathrm{m}^{2}$. For the lasing properties of PF-1, we found a lasing threshold of around $75 \mu \mathrm{J}$ and a tunability of $20 \mathrm{~nm}$. These values are comparable with those of rhodamine 6G, a well-known laser dye.
\end{abstract}

Keywords: fluorene cross-conjugated polymer; polymer light emitting diodes (PLEDs); lasing properties

\section{Introduction}

Since the first report of electroluminescence in conjugated polymers in 1990 [1], numerous materials of this kind have been designed and synthesized to be used as active compounds for polymer light-emitting diodes (PLEDs). Over the last two decades great progress has been made in these materials reaching internal quantum efficiencies of approximately $100 \%[2,3]$. PLEDs have several advantages with respect to solid-state inorganic semiconductors, such as flexibility, fast processing and ease of deposition in thin films with good morphology by simple techniques such as spin-coating [4]. Nowadays, PLEDs and OLEDs (Light-Emitting diodes made of organic molecules of low molecular weight) are widely used in flat panel displays of several devices such as digital cameras, mobile phones and televisions [5]. Nevertheless, two of the challenges faced by the field of electro-luminance devices 
are to improve the manufacturing process including deposition methods, and the design of novel chemical structures with high fluorescence quantum yield which increases the emission spectrum and current-voltage characteristics [6-9]. The use of highly fluorescent materials, such as oligomers and polymers, opens the possibility of improving the PLEDs' performance [8,10]. Among the wide variety of materials used for PLEDs, fluorene-based polymers show interesting and unique chemical and physical properties such as a rigid planar biphenyl unit, which improves solubility, as well as thermal stability and processability [10-12]; they comprise aromatic segments which help to reduce the turn-on voltage $\left(V_{\text {on }}\right)$ that results from a good balance in electron and hole injection $[13,14]$.

Fluorene-based polymers are also under active research for other applications such as: organic photovoltaic (OPV) cells [15,16], two- and three-photon absorption phenomena [17-20], multiphoton fluorescence and imaging [21], two-photon micro-fabrication [22,23], optical power limiting [24,25] and optical data storage [26]. On the other hand, cross-conjugated compounds are relatively unexplored as active materials in optoelectronic or photonic devices; they can be found as quinones, radialenes, fulvalenes and fused aromatics [27]. Cross-conjugated systems have been implemented as PLEDs [28], nonlinear optical materials, and magnetic materials, and they also favor donor-acceptor interactions [29-32]. When the cross-conjugated polymer chain is connected to a donor material, a strong intramolecular charge transfer is observed, leading to high fluorescence intensities [30]. Motivated by this emission property, our group had previously synthesized the fluorene cross-conjugated polymer (PF-1), whose chemical structure is shown in Figure 1, and used this material to develop organic nanoparticles which exhibit very intense fluorescence induced by two-photon absorption in the wavelength range between 740 and $820 \mathrm{~nm}$; these advantageous properties of nanoparticles of PF-1 were used to implement their use in multiphoton microscopy [31]. Likewise, we demonstrated coherent frequency conversion within the telecommunication wavelength band (1100-1600 $\mathrm{nm})$ [32].

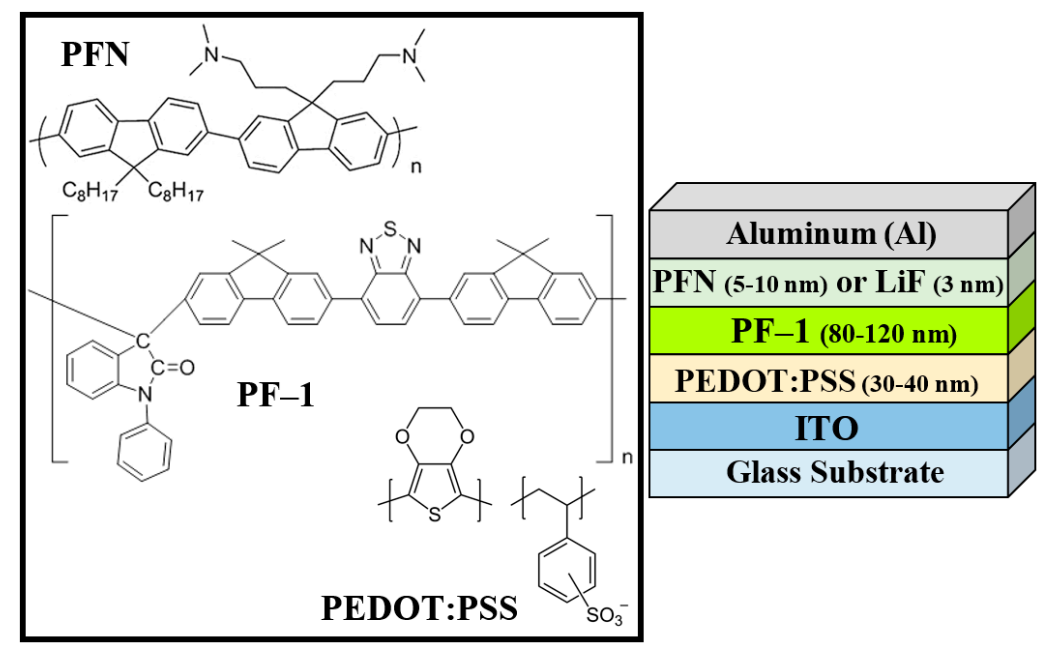

Figure 1. Chemical structure of PFN, conjugated polymer PF-1, and PEDOT:PSS; and PLEDs architecture.

Based on the above discussion of fluorene polymers and cross-conjugated compounds, and motivated by the excellent properties of PF-1 (intense and broad emission band, solubility at high concentrations and easy processability into thin solid films of good quality), in this work we study the photophysical and electroluminescence characteristics of $\mathbf{P F - 1}$ as an active material in an optoelectronic application (PLEDs) and in lasing. The conducting characteristics of this cross-conjugated polymer were studied with a simple PLED architecture in which a thin active layer of PF-1 was sandwiched between the hole injector sheet poly(2,3-dihydrothieno-1,4-dioxin)-poly(styrenesulfonate) (PEDOT:PSS) and the electron injector 
films poly[(9,9-bis(3'-(N,N-dimethylamino)propyl)-2,7-fluorene)-alt-2,7-(9,9-dioctylfluorene)] (PFN) or lithium fluoride (LiF), (see Figure 1). Our PLEDs' performance was compared against other electroluminescent materials reported in the same spectral region, finding that the turn-on voltage $\left(V_{\text {on }}\right)$ and the efficiency compare favorably. On the other hand, PF-1 exhibits good lasing properties in solution. The laser threshold and laser tunability range of PF-1 were measured and compared with the well-known laser dye rhodamine $6 \mathrm{G}$ and with other materials tested as gain media. Our results show that the cross-conjugated polymer PF-1 is a promising candidate for PLEDs and lasing applications.

\section{Materials and Methods}

\subsection{Materials}

Synthesis of the fluorene derivative monomer 4,7-bis[2-(9,9-dimethyl)fluorenyl] benzo[1,2,5] thiadiazole and its cross-conjugated polymer (PF-1) were reported elsewhere [32]. The molecular structure of PF-1 and the PLED architecture are shown in Figure 1. Linear absorption and lasing measurements were performed in solution with a concentration of $10^{-4} \mathrm{M}$ using chlorobenzene (purchased from Sigma-Aldrich, Mexico), as solvent.

PLEDs were fabricated using an Indium Tin Oxide (ITO)-covered glass substrate ultrasonically cleaned for $30 \mathrm{~min}$ in each of the following baths: distilled water, ethanol and an alkaline solution (Hellmanex II mixed with water). These substrates were coated by spin-coating with PEDOT:PSS to create a hole injector film (40-50 nm thick) and annealed in air at $120{ }^{\circ} \mathrm{C}$. The emitter layer was deposited from a solution of PF-1 dissolved in chlorobenzene $(6 \mathrm{mg} / \mathrm{mL})$, and consisted of an $80-120 \mathrm{~nm}$ thick film covering $0.09 \mathrm{~cm}^{2}$ of active area. Deposition was done in a glove box under a nitrogen atmosphere. Once deposited, the organic films were annealed (in presence of air) at $120^{\circ} \mathrm{C}$ for $20 \mathrm{~min}$. Two different sets of PLEDs were prepared with the commonly used electron injectors PFN and LiF. The LiF layer was deposited by vacuum evaporation and had a thickness of $3 \mathrm{~nm}$. It is worth noting that the typical LiF thickness for this type of device is between 0.5 and $2 \mathrm{~nm}[33,34]$; however, our $3 \mathrm{~nm} \mathrm{LiF}$ layer resulted after optimization of the PLED performance. For films below $3 \mathrm{~nm}$, by using AFM analysis, we observed physical damage in the PF-1 layer after deposition of the Aluminum (Al) cathode. PFN layer was deposited by spin-coating $(\approx 10 \mathrm{~nm}$ of thickness) and annealed at $80{ }^{\circ} \mathrm{C}$ for $20 \mathrm{~min}$. Finally, the $\mathbf{A l}$ cathode was deposited by thermal evaporation with a thickness of $100 \mathrm{~nm}$. Morphological and film thickness measurements were performed by Atomic Force Microscopy (AFM) (Nanosurf, easyscan2, Woburn, MA, USA) operating in contact mode with a scanning area of $10 \mu \mathrm{m} \times 10 \mu \mathrm{m}$. For future comparison of surface roughness $(\mathrm{R} \alpha)$ presented in Section 3.1 between PF-1 and poly[2-methoxy,5-(2'-ethylhexyloxy)-1,4-phenylene-vinylene] (MEH-PPV) films, according to [35]: “A $180 \mathrm{~nm}$ ITO film was grown. ITO glasses were cleaned by sequential ultrasonification in trichloroethylene, acetone, and methanol solvents for a total of $30 \mathrm{~min}$. A thin layer of polyethylene dioxythiophene doped with polystyrene-sulfonic acid (PEDOT:PSS, Sigma-Aldrich) was spin-coated at $4000 \mathrm{rpm}$ for $30 \mathrm{~s}$ on the cleaned ITO-coated glass substrate. Typical thicknesses of $70 \mathrm{~nm}$ resulted. The thin layers were then dried at $100{ }^{\circ} \mathrm{C}$ for $30 \mathrm{~min}$. Spin-coating for photoactive layer deposition was kept at $3000 \mathrm{rpm}$ to obtain a smoother surface with $150 \mathrm{~nm}$ active layer thickness. A $90 \mathrm{~nm} \mathrm{Al}$ cathode layer was deposited on the active layer by thermal evaporation".

\subsection{Experimental}

Steady-state linear absorption spectra were acquired, in solution, using a spectrophotometer (Perkin Elmer, Lambda 900, Waltham, MA, USA) over a range of 280 to $700 \mathrm{~nm}$. Fluorescence emission curves were recorded with a portable spectrometer (Ocean Optics, USB4000, Dunedin, FL, USA); samples were illuminated with an UV light lamp source. The current density versus voltage (J-V) and luminous efficiency versus voltage (L-V) curves were measured simultaneously using a power supply (Newark element I4, Keithley 2400, Palatine, IL, USA) over a range of $0-14 \mathrm{~V}$ with an in-house-designed and calibrated detection system. The J-V curve is recorded by direct processing of data sent from 
the used Keithley 2400 apparatus. Luminous density is estimated through the voltage delivered by a photodiode located at fixed distance from the PLED. Photodiode calibration was performed by using the luminance of commercial LEDs, at different wavelengths and considering all geometrical parameters involved in the detection system. Signal was previously quantified by a highly sensitive lux meter and correlated with the photodiode voltage response. All data acquisition routines were automated by using LabVIEW software specially designed for this purpose. PLEDs emission was characterized under atmospheric conditions.

For the PF-1 laser emission studies, a $10 \mathrm{~mm}$ fluorometric quartz cuvette was placed in a flat nondispersive resonator and transversely pumped at $425 \mathrm{~nm}$ by an Optical Parametric Oscillator (OPO) system (Flexiscan, GWU Laser Technik, Germany) with maximum energy of $180 \mathrm{~mJ}$ and $6 \mathrm{~ns}$ pulse duration. The OPO was pumped by the third harmonic $(355 \mathrm{~nm})$ of a Nd:YAG laser (Spectra Physics, Quanta-Ray, Santa Clara, CA, USA) operating at $10 \mathrm{~Hz}$ in the nanosecond regime. The light beam from the OPO was focused by a cylindrical lens (focal distance $100 \mathrm{~mm}$ leading to spot line of area $\sim 0.01 \mathrm{~cm}^{2}$ ) into a PF-1 solution with $10^{-4} \mathrm{M}$ concentration using chlorobenzene as solvent. The beam energy was varied using neutral density filters and the spectral width of the laser emission was determined by a spectrometer (Ocean Optics, USB4000, Dunedin, FL, USA) with a spectral resolution of $0.7 \mathrm{~nm}$. Laser emission cross-section for stimulated emission was calculated according to reference [36]. In order to tune the emission wavelength of the PF-1 solution, we replaced one of the resonator flat mirrors with a diffraction grating mounted on a kinematic stage. The experimental setup is shown in Figure 2.

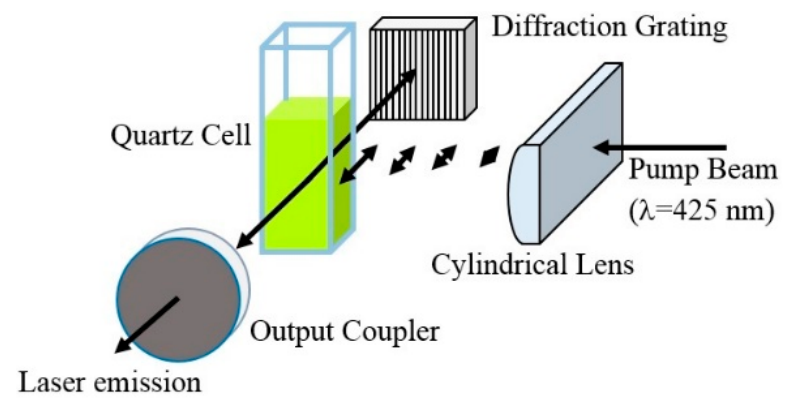

Figure 2. Experimental setup for lasing characterization.

Finally, fluorescence lifetime was obtained through time-correlated single photon counting (TCSPC) with a fluorescence lifetime system (Horiba, Tempro, Japan) equipment by using $370 \mathrm{~nm}$ nanoLEDs for excitation. PF-1 sample was analyzed in chloroform solution (OD at $370 \mathrm{~nm}<0.1$ ). A $0.01 \%$ suspension of Ludox AS40 (Sigma-Aldrich, Mexico) in ultrapure water was used for the prompt signal. Calibration of the equipment was performed with a [1,4-bis(4-methyl-5-fenil-2-oxazolyl)benzene] (POPOP) methanol solution (optical density $<0.1$ and lifetime of $0.93 \mathrm{~ns}$ [37]). Data were fit with the software DAS6 available in the equipment.

\section{Results and Discussion}

\subsection{PLEDS}

Absorption and fluorescence spectra of PF-1 in a solution of chlorobenzene and its electroluminescence spectrum in solid state are shown in Figure 3a. Here, two bands of maximum absorption are observed: a peak centered at $323 \mathrm{~nm}$ with a full width at half maximum (FWHM) close to $50 \mathrm{~nm}$ and a secondary peak with amplitude reaching almost $50 \%$ of the previous one, at $427 \mathrm{~nm}$ with a FWHM of approximately $75 \mathrm{~nm}$. 


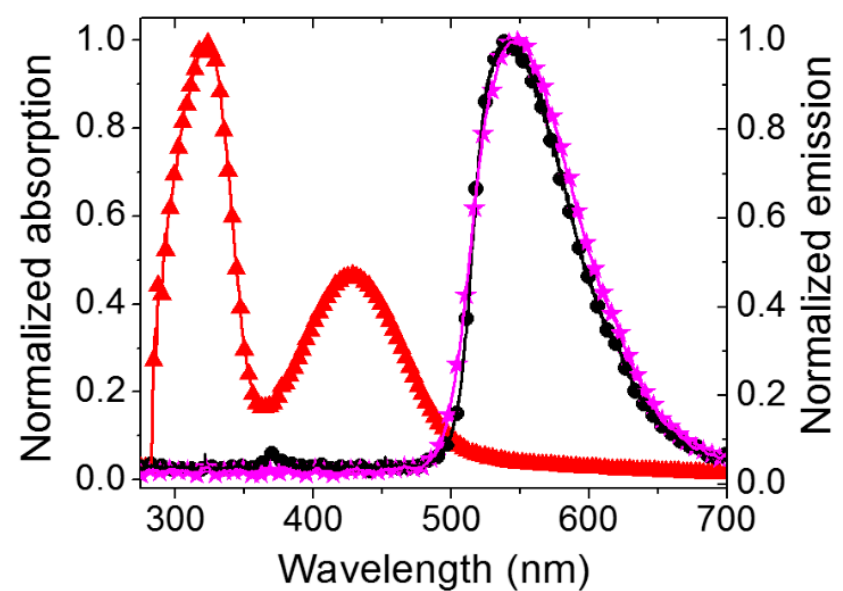

a)

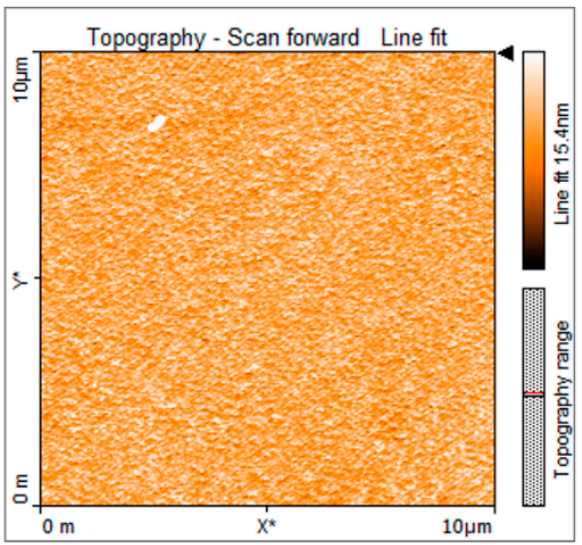

b)

Figure 3. (a) Normalized absorption (red triangles), fluorescence emission (black circles), both in solution of chlorobenzene, and electroluminescence emission (purple stars) in solid state of PF-1; (b) AFM image of a PF-1 thin film surface $\left(R_{\alpha}\right.$ of the order of $\left.1.4 \mathrm{~nm}\right)$.

The absorption peak centered at $323 \mathrm{~nm}$ is attributed to the $\pi-\pi^{*}$ transition of the conjugated chain. The second peak centered at $427 \mathrm{~nm}$ is associated with the $\mathrm{n}-\pi^{*}$ transition of the benzothiadiazole, according to calculations presented in reference [29]. Both the steady-state fluorescence (black circles) and electroluminescence (purple stars) curves show emission peaks of PF-1 in the green-yellow region with broad emission bands centered at $544 \mathrm{~nm}$ (FWHM of $80 \mathrm{~nm}$ ) and $551 \mathrm{~nm}$ (FWHM of $90 \mathrm{~nm}$ ), respectively. Fluorescence quantum yield in solution was determined to be close to one [31]. These results indicate that $\mathbf{P F}-\mathbf{1}$ is able to recombine excitons efficiently; therefore, it is interesting to study the potential of the material for applications such as PLEDs or lasing.

PF-1 solutions with different concentrations were prepared, observing a high solubility without aggregated molecules. Good solubility, among other properties of polymers, is important in order to process them into high quality thin films using wet processes, i.e., spin-coating. For instance, the surface quality of the deposited films is critical for device performance since it influences the charge injection, mobility and recombination properties on the active film; it also influences the contact quality between the emitter layer and the hole and electron injector materials. Thus, this parameter could largely improve PLEDs' emission efficiency. Figure 3b shows a surface topography image of the PF-1 layer used for our PLEDs; the image covers an area of $10 \mu \mathrm{m} \times 10 \mu \mathrm{m}$. As seen in the figure, there exists a good surface roughness $\left(R_{\alpha}\right)$ quality in our samples $\left(R_{\alpha}\right.$ of the order of $\left.1.4 \mathrm{~nm}\right)$. This number is in fact smaller than those typical values for the widely and previously used MEH-PPV polymer ( 7-14 nm [35], deposited under very similar experimental conditions to those in this work, see Section 2.1), and ITO ( 4-24 nm [38]).

Results from the measurements of current and luminosity as a function of the applied voltage for PLEDs comprising PFN or LiF as an electron injector layer are shown in Figure 4a. For the J-V curves, it is observed that the current increases over the range $4-10 \mathrm{~V}$, reaching a maximum at approximately over $120 \mathrm{~A} / \mathrm{m}^{2}$ for both devices. For PLEDs containing PFN (black circles), the luminous density increases sharply until $878 \mathrm{~cd} / \mathrm{m}^{2}$ in the range $4.5-5 \mathrm{~V}$. This increment is due to a lowering of the effective barrier height for the electron injection by PFN which leads to a more balanced injection of electrons and holes in the emitting layer [39]. PFN film creates a positive interface that induces a negative dipole potential for electrons, allowing their fast transfer between the $\mathbf{A l}$ metal cathode and the emitting polymer [39]. For voltages greater than approximately $5.5 \mathrm{~V}$, the current density continues increasing although the luminous density seems to saturate, which could be due to limitations in the used photodetector; thus, it is probable that our reported PLED would be even more efficient. The energy level arrangement of the system is shown in Figure $4 \mathrm{~b}$. Here it is observed that PFN creates 
a potential barrier between the cathode and $\mathbf{P F - 1}$, allowing the transport of electrons by tunneling, and thus increasing the electron population in PF-1; this in turn leads to an increment of the luminous density of the device since PF-1, due to its light emission properties, can be cataloged as a good emitter material.

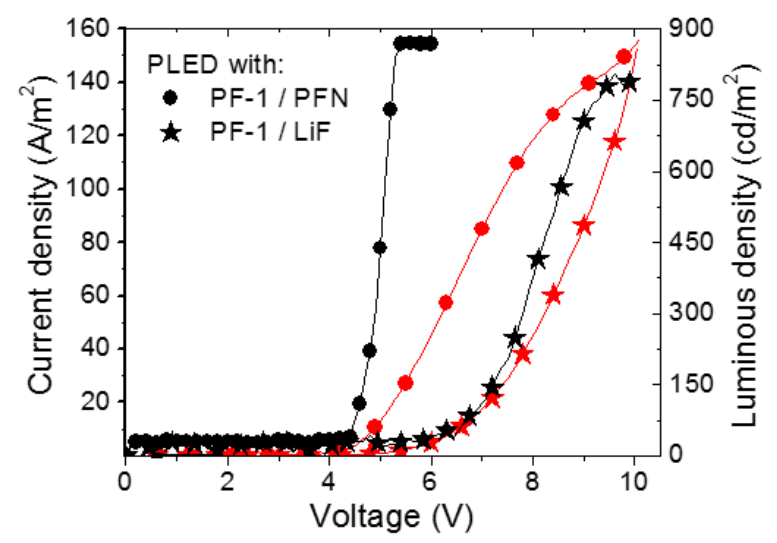

a)

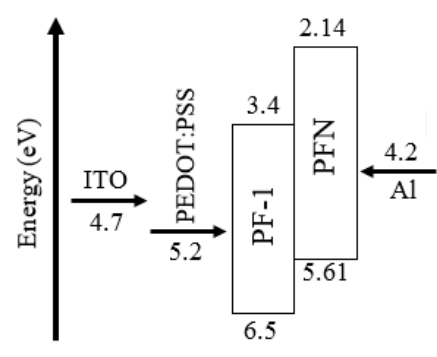

b)

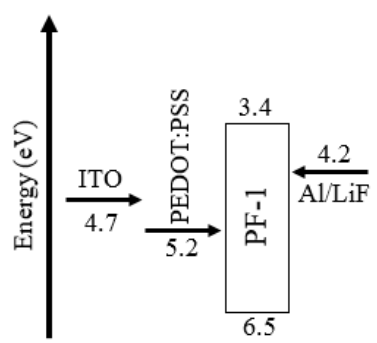

c)

Figure 4. (a) Current density (red symbols) and luminous density (black symbols) as a function of applied voltage for PLEDs containing PFN (circles) and LiF (stars) as electron injectors, respectively. Schematic energy diagram for HOMO and LUMO levels for PLEDs with (b) PFN and (c) LiF.

PLEDs based on LiF showed an increase in the luminous density reaching a maximum of $805 \mathrm{~cd} / \mathrm{m}^{2}$ over a range between 6.5 to $9.5 \mathrm{~V}$ (see black stars in Figure 4a). Electrons are injected by tunneling over the potential barrier formed between the $\mathbf{A l}$ cathode and the emitter material, as shown in Figure 4c [40].

Results for the luminous efficiency of PLEDs containing PFN and LiF versus applied voltage and current density are shown in Figure 5a,b, respectively. It is seen that PLEDs fabricated with PFN (black circles) (Figure 5a) have a turn-on voltage between 4 and $4.5 \mathrm{~V}$ and a maximum efficiency of $40 \mathrm{~cd} / \mathrm{A}$ at $5.5 \mathrm{~V}$. Similar behavior is displayed in Figure $5 \mathrm{~b}$ where an increase in the efficiency is presented from 12.5 to $40 \mathrm{~cd} / \mathrm{A}$ over a range of $0-20 \mathrm{~A} / \mathrm{m}^{2}$, followed by a decrease in the efficiency to $17.5 \mathrm{~cd} / \mathrm{A}$ which extends to $50 \mathrm{~A} / \mathrm{m}^{2}$. In regards to the PLEDs containing LiF (red stars in Figure $5 \mathrm{a}, \mathrm{b}$ ), the turn-on voltage was slightly over $6.5 \mathrm{~V}$, and the maximum efficiency was around $9 \mathrm{~cd} / \mathrm{A}$, at $8 \mathrm{~V}$ (see Figure 5a). From Figure 5b, a low variation in efficiency is observed over the range between 5 to $70 \mathrm{~A} / \mathrm{m}^{2}$, with its maximum at $30 \mathrm{~A} / \mathrm{m}^{2}$. Both PLEDs' architectures show a maximum luminous density above $800 \mathrm{~cd} / \mathrm{m}^{2}$. This can be explained because the strongly polarizable central fragment and the "isatin" unit of PF-1 allows electrons and holes to be transported efficiently along the polymer chain in order to be recombined. From our results, it is clear that PLEDs with PFN as the electron injection film show lower turn on-voltage and better efficiency than PLEDs containing LiF. 


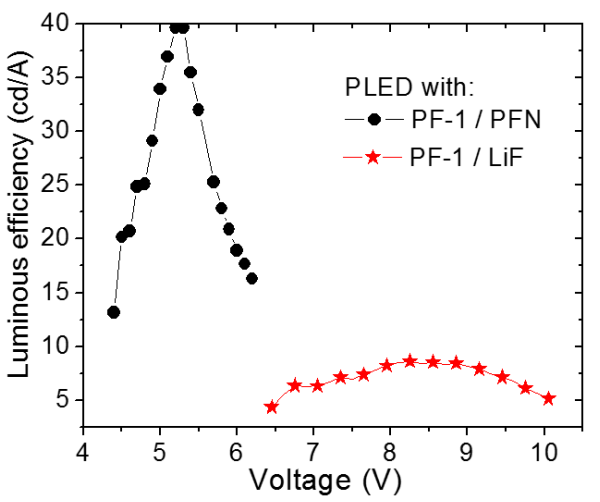

a)

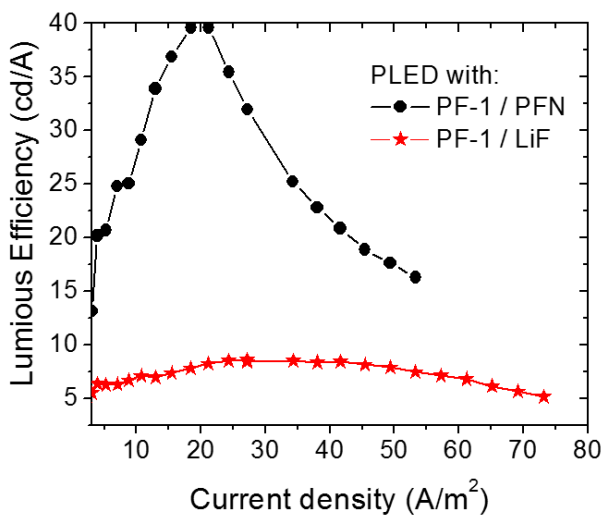

b)

Figure 5. Luminous efficiency of PLEDs based on PF-1 polymer with the electron injectors PFN and LiF as a function of (a) applied voltage, and (b) current density.

Our PLEDs compare favorably to other electroluminescent devices recently reported in the literature with similar emission wavelengths and architecture. Szlachcic et al. [41] achieved a luminous density of $600 \mathrm{~cd} / \mathrm{m}^{2}$ at $8 \mathrm{~V}$ but they did not report the luminous efficiency; here, the helical fused azulene (DDH) as an emitter was used. Poloek et al. [42] obtained a luminous efficiency of $25.9 \mathrm{~cd} / \mathrm{A}$ at $9 \mathrm{~V}$ with approximately $1000 \mathrm{~cd} / \mathrm{m}^{2}$ with a heteroleptic platinum complex (FPtppND); Kumar Gupta et al. [43] reported a luminous efficiency of $1.71 \mathrm{~cd} / \mathrm{A}$ at $10 \mathrm{~V}$ with a luminous density of $10 \mathrm{~cd} / \mathrm{m}^{2}$ for a cross-linking polymer (PIM-1). Also, the efficiency compares favorably with that reported by Diken et al. [44] for much more complex copolymers containing carbazole and oxadiazole (PPV derivatives such as MEH-PPV) doped with a host triplet emitter material (carbazole homopolymer) with luminous efficiencies of $0.43,15$ and $23 \mathrm{~cd} / \mathrm{A}$. From this comparison, we conclude that our PLEDs can be considered as potential candidates for electroluminescence applications. Table 1 summarizes our results and some comparisons between different organic emitter materials.

Table 1. Parameters of PF-1 PLEDs and their comparison with other organic electroluminescent materials with similar emission wavelengths.

\begin{tabular}{cccccc}
\hline Material & $\begin{array}{c}\lambda \text { of Emission } \\
(\mathbf{n m})\end{array}$ & $\begin{array}{c}\text { Turn on } \\
\text { voltage }\end{array}$ & $\begin{array}{c}\text { Luminous density } \\
\left(\mathbf{c d} / \mathbf{m}^{\mathbf{2}}\right)\end{array}$ & $\begin{array}{c}\text { Efficiency } \\
\text { (cd/A) }\end{array}$ & Ref. \\
\hline PF-1 /PFN & 551 & 4.5 & 878 & 40 & This work \\
PF-1/LiF & 551 & 6.5 & 805 & 9 & This work \\
DDH & 555 & 8 & 600 & NA & {$[41]$} \\
FPtppND & 545 & 9 & 1000 & 25.9 & {$[42]$} \\
PIM-1 & 515 & 10 & 10 & 1.71 & {$[43]$} \\
Carbazole & $527^{\mathrm{a}}$ & 5 & NA & $0.45-15,23^{\mathrm{b}}$ & {$[44]$} \\
homopolymer & & & & & \\
\hline
\end{tabular}

${ }^{a}$ Emission of triplet states; ${ }^{b}$ Luminous efficiencies for different concentrations of TPBI exciton blocking.

\subsection{Lasing of PF-1 Compound}

Most of the research in the field of polymer lasers focuses on creating materials with high optical gain, leading to a reduction of the laser threshold. As discussed before, the thermal and photochemical stability, high quantum yield of fluorescence and the possibility of being incorporated in solid-state matrices make PF-1 a possible candidate for laser applications. Figure 6a shows the laser line emitted from a PF-1 solution $\left(10^{-4} \mathrm{M}\right.$, in chlorobenzene) pumped at $10 \mathrm{~Hz}$ at the wavelength of $425 \mathrm{~nm}$ with pulses of $6 \mathrm{~ns}$ giving a peak power of $13 \mathrm{~kW}$, focused on a spot line with an area of $\sim 0.01 \mathrm{~cm}^{2}$, with 
a corresponding fluence and intensity of $7.8 \mathrm{~mJ} / \mathrm{cm}^{2}$ and $1.3 \mathrm{MW} / \mathrm{cm}^{2}$. This light peak is centered at $566 \mathrm{~nm}$ with a FWHM of approximately $3.8 \mathrm{~nm}$. To obtain the tunability range of the laser, the resonator flat mirror was replaced with a diffraction grating, finding tunability from 555 to $575 \mathrm{~nm}$ as shown in the inset of Figure 6a. Outside of this range, laser output was observed but its intensity was not constant. A laser threshold at $566 \mathrm{~nm}$ of around of $75 \mu \mathrm{J}\left(7.5 \mathrm{~mJ} / \mathrm{cm}^{2}\right)$ was found, as shown in Figure $6 \mathrm{~b}$. Also, Figure $6 \mathrm{~b}$ shows two effects directly related to the pump energy; a constant reduction of the FWHM (filled triangles) of the emission band in the range 10-75 $\mu \mathrm{J}$; fluorescence; and a constant increase in the lasing intensity (open circles) in the range 75-160 $\mu \mathrm{J}$. The cross-section $\sigma_{\mathrm{e}}$ for the stimulated emission was calculated according to [36]:

$$
\sigma_{e}=\frac{\lambda_{e}^{4} E(\lambda) \varphi_{f}}{8 \pi c_{0} n^{2} \tau_{f}}
$$

where $\lambda_{\mathrm{e}}$ is the emission wavelength, $n$ is the refractive index of the solvent, $c_{o}$ is the velocity of light, $\tau_{f}$ is the fluorescence lifetime, $E(\lambda)$ is the normalized fluorescence line-shape function and $\phi_{f}$ is the quantum yield. Figure $6 \mathrm{c}$ shows the fluorescence decay of PF-1 in a semi-log plot and fit to a line giving a lifetime $\tau_{f}$ of $4.9 \mathrm{~ns}$. The calculated value of $\sigma_{\mathrm{e}}$ is $4.24 \times 10^{-16} \mathrm{~cm}^{2}$, which is comparable with values reported recently for materials considered to be good laser dyes [36,37].

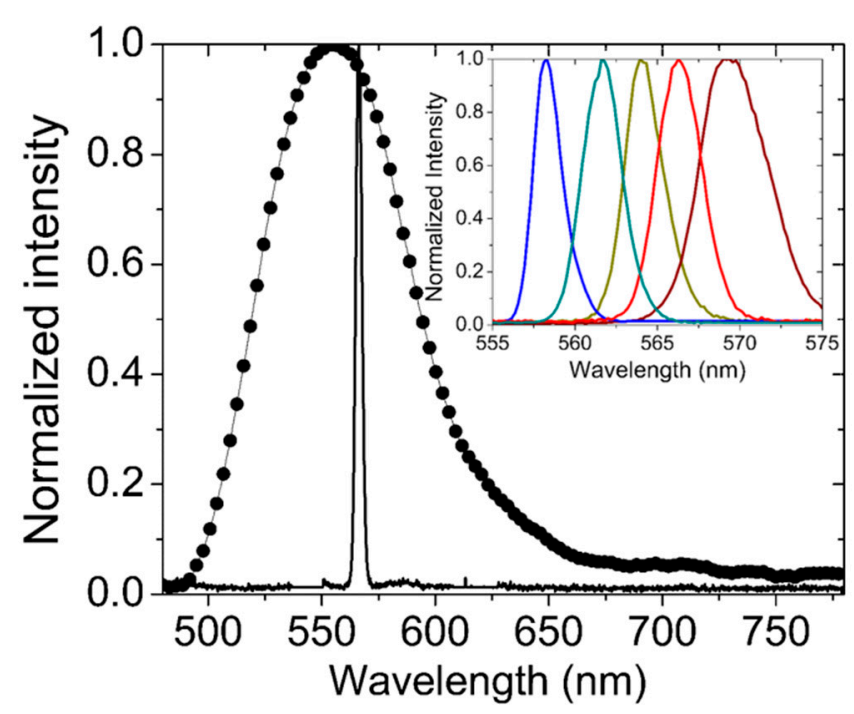

a)

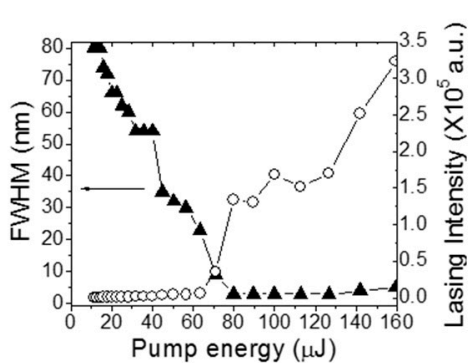

b)

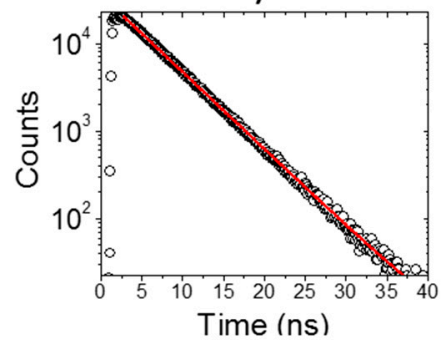

c)

Figure 6. (a) Fluorescence (circles) and lasing (narrow line) of PF-1 in chlorobenzene solution. Inset, tunability of PF-1 lasing; (b) FWHM and lasing intensity of $566 \mathrm{~nm}$ emission for a solution of PF-1 as a function of the pump energy; (c) PF-1 fluorescence lifetime.

The laser threshold and the stimulated cross-section of PF-1 compare well against the standard and widely used laser dye rhodamine 6G (laser threshold 70-75 $\mu \mathrm{J}$, intensity $4.4 \mathrm{MW} / \mathrm{cm}^{2}$, fluorescence lifetime of $3.9 \mathrm{~ns}$, quantum yield 0.89 , laser emission cross-section $4.17 \times 10^{-16} \mathrm{~cm}^{2}$ ) [45-48]. PF-1 as gain medium compares favorably to other materials recently reported in the literature. El-Daly et al. reported for dyes 3-(4-dimethylamino-phenyl)-1-(2,5-dimethyl-furan-3-yl)-propenone (DDFP) [36] and POPOP [37] fluorescence times of 2.3 and $0.93 \mathrm{~ns}$ and laser emission cross-sections of $3.23 \times 10^{-16} \mathrm{~cm}^{2}$ and $2.82 \times 10^{-16} \mathrm{~cm}^{2}$, respectively. Direct comparison of the lasing parameters is shown in Table 2. Regarding the lasing properties of PF-1, the higher cross-section of the stimulated emission and fluorescence lifetime compared with other materials (see Table 2) can be attributed to the large population of excited species associated with $\pi-\pi^{*}$ and $n-\pi^{*}$ transitions and 
the creation of electron-hole pairs located on different conjugated segments along the polymer chain. These electron-hole pairs can move along the polymer chain to reach the recombination length path causing longer-lived stimulated emission effects leading to extended fluorescence lifetimes [49-52]. In this regard, Pauck et al. [49] concluded that the amplitude as well as the lifetime of the stimulated emission is increased in diluted LPPP polymer blends with well-separated chains. A similar conclusion was stated by Yan et al. [50] and Rothberg et al. [51] for blends of soluble PPV. In contrast, optical pumping of laser dyes (such as rhodamine 6G, POPOP and DDFP) is usually achieved in high-lying vibrionic levels of the excited state, followed by an ultrafast vibrational relaxation causing an inversion of population and finally emission. In terms of laser physics the situation described above corresponds to a four-level system. From the mentioned comparisons and based in these attractive properties exhibited by $\mathbf{P F - 1}$, such as broad absorption and emission spectra, efficient photoluminescence emission and ease of processing, it is possible to position it as a potential candidate for laser applications.

Table 2. Laser emission cross-section $\left(\sigma_{\mathrm{e}}\right)$, lifetime of fluorescence $\left(\tau_{\mathrm{f}}\right)$ and $\lambda$ of maximum lasing for PF-1 polymer and comparison with other organic materials used as laser gain media.

\begin{tabular}{ccccccc}
\hline Material & Solvent & $\begin{array}{c}\lambda \text { of maximum } \\
\text { lasing }(\mathbf{n m})\end{array}$ & $\begin{array}{c}\sigma_{\mathbf{e}} \times \mathbf{1 0}^{-16} \\
\mathbf{c m}^{\mathbf{2}}\end{array}$ & $\tau_{\mathbf{f}}(\mathbf{n s})$ & $\begin{array}{c}\text { Fluorescence } \\
\text { range (nm) }\end{array}$ & Ref. \\
\hline PF1 & Clorobnezene & 566 & 4.24 & 4.9 & $520-600$ & This work \\
Rhodamine 6G & Ethanol & 566 & 4.17 & 3.9 & $530-590$ & {$[46,47]$} \\
POPOP & Methanol & 555 & 2.82 & 0.93 & $400-460$ & {$[36]$} \\
DDFP & DMSO & 515 & 3.23 & 2.3 & $470-535$ & {$[37]$} \\
\hline \multicolumn{2}{r}{ a in methanol solution. }
\end{tabular}

\section{Conclusions}

Light emission properties of PF-1 under electrical and optical excitation have been studied. We implemented PLEDs based on PF-1 polymer with two widely used electron injectors, PFN and $\mathbf{L i F}$, in order to improve the performance and to compare them with devices emitting in the same spectral region reported by other groups. The following parameters were measured: for PLEDs with PFN as the electron injector layer, a $V_{\text {on }} \sim 4.5 \mathrm{~V}$, luminance of $878 \mathrm{~cd} / \mathrm{m}^{2}$ at $5.5 \mathrm{~V}$ and $20 \mathrm{~A} / \mathrm{m}^{2}$; and for PLEDs with $\mathrm{LiF}, \mathrm{V}_{\text {on }} \sim 6.5 \mathrm{~V}$, luminance of $805 \mathrm{~cd} / \mathrm{m}^{2}$ at $9.5 \mathrm{~V}$ and $40 \mathrm{~A} / \mathrm{m}^{2}$. In the case of PFN a very acceptable luminous efficiency at low current density and on-voltage have been reached. Meanwhile, PLEDs that contained LiF showed a luminous efficiency that remained approximately constant during a range of current density between 0 and $75 \mathrm{~A} / \mathrm{m}^{2}$. It is concluded that PF-1 is a good emitter material that favors an efficient transport of electrons and holes in order to be recombined. Lasing properties measured for PF-1 found a low threshold (around $75 \mu \mathrm{J}$, fluence and intensity of $7.5 \mathrm{~mJ} / \mathrm{cm}^{2}$ and $1.25 \mathrm{MWcm}^{2}$, respectively) for laser emission and a tunability of $25 \mathrm{~nm}$. These values are reasonable in comparison with those of the standard laser dye rhodamine 6G. These light emission studies of PF-1 show a robust cross-conjugated polymer and position it as a good candidate for electroluminescent devices as well as for possible implementation in laser applications.

Acknowledgments: Authors acknowledge financial support from DGAPA-UNAM (PAPIIT IN 105314-3) and CONACYT (grants 131467, 215708 and 151842), CONACyT-SENER 153094, CeMIE-Sol 207450/27 call 2013-02, Fondo Sectorial CONACYT-SENER-SUSTENTABILIDAD ENERGETICA; as well as assistance from the Spectroscopy, Materials and Ultrafast Optics Laboratories of the Optical Research Center. Sergio Romero-Servin acknowledges a doctoral scholarship from CONACYT.

Author Contributions: Sergio Romero-Servin implemented the experimental set up for lasing measurements, analyzed data, and contributed to the manuscript writing and discussion, and together with Luis-Abraham Lozano-Hernández performed all measurements. Ramón Carriles, Gabriel Ramos-Ortíz and José-Luis Maldonado conceived the main ideas of this research and provided financial support, reviewed this article and discussed results and data. Enrique Pérez-Gutiérrez helped with the fabrication and characterization of PLEDs and provided fruitful discussion on these devices results. Ullrich Scherf synthesized and characterized the fluorene monomers for PF-1 and Mikhail G. Zolotukhin synthesized and chemically-structurally characterized the polymer PF-1. 
Conflicts of Interest: The authors declare no conflict of interest.

\section{References}

1. Burroughes, J.H.; Bradley, D.D.C.; Brown, A.R.; Mackay, K.; Friend, R.H.; Burns, P.L. Light-emitting diodes based on conjugated polymers. Nature 1990, 347, 539-541. [CrossRef]

2. Reineke, S.; Lindner, F.; Schwartz, G.; Seidler, N.; Walzer, K.; Lussem, B. White organic light-emitting diodes with fluorescent tube efficiency. Nature 2009, 459, 234-239. [CrossRef] [PubMed]

3. Adachi, C.; Baldo, M.A.; Thompson, M.E.; Forrest, S.R. Nearly 100\% internal phosphorescence efficiency in an organic light-emitting device. J. Appl. Phys. 2001, 90, 5048-5051. [CrossRef]

4. Kalyani, N.; Dhoble, S. Organic light emitting diodes: Energy saving lighting technology-A review. Renew. Sust. Energ. Rev. 2012, 16, 2696-2723. [CrossRef]

5. Kalyani, N.; Dhoble, S. Novel approaches for energy efficient solid state lighting by RGB organic light emitting diodes-A review. Renew. Sust. Energ. Rev. 2014, 32, 448-467.

6. Chuang, C.; Chang, C.; Chang, C.; Wang, Y.; Lin, Y.; Leung, M. Poly(9,9-dialkylfluorene-cotriphenylamine)s-A family of photo-curable hole-transport polymers for polymer light-emitting diodes applications. Eur. Polym. J. 2014, 56, 33-44. [CrossRef]

7. Wang, J.; Zhang, F.; Zhang, J.; Tang, W.; Tang, A.; Peng, H.; Xu, Z.; Teng, F.; Wang, Y. Key issues and recent progress of light efficient organic light-emitting diodes. J. Photochem. Photobiol. C 2013, 17, 69-104. [CrossRef]

8. Chen, Z.; Liang, J.; Han, X.; Yin, J.; Yu, G.; Liu, S. Fluorene-based novel highly emissive fluorescent molecules with aggregate fluorescence change or aggregation-induced emission enhancement characteristics. Dyes Pigments 2015, 112, 59-66. [CrossRef]

9. Pu, Y.; Chiba, T.; Ideta, K.; Takahashi, S.; Aizawa, N.; Hikichi, T.; Kido, J. Fabrication of organic light-emitting devices comprising stacked light-emitting units by solution-based processes. Adv. Mater. 2015, 27, 1327-1332. [CrossRef] [PubMed]

10. Tao, S.; Peng, Z.; Zhang, X.; Wang, P.; Lee, C.-S.; Lee, S.-T. Highly efficient non-doped blue organic light-emitting diodes based on fluorene derivatives with high thermal stablity. Adv. Funct. Mater. 2005, 15, 1716-1721. [CrossRef]

11. Scherf, U.; List, E. Semiconducting polyfluorenes-Towards reliable structure-property relationships. Adv. Mater. 2002, 14, 477-487. [CrossRef]

12. Klaerner, G.; Miller, R.D. Polyfluorene derivatives: Effective conjugation lengths from well-defined oligomers. Macromolecules 1998, 31, 2007-2009. [CrossRef]

13. Feng, X.J.; Chen, S.; Ni, Y.; Wong, M.; Lam, M.; Cheah, K.; Lai, G. Fluorene derivatives for highly efficient non-doped single-layer blue organic light-emitting diodes. Org. Electron. 2014, 15, 57-64. [CrossRef]

14. Feng, L.; Zhang, C.; Bie, H.; Chen, Z. Synthesis and photoluminescent properties of some novel fluorene derivatives. Dyes Pigments 2005, 64, 31-34. [CrossRef]

15. Beaupre, S.; Boudreault, P.; Leclerc, M. Solar-energy production and energy-efficient lighting: Photovoltaic devices and white-light-emitting diodes using poly(2,7-fluorene), poly(2,7-carbazole), and poly(2,7-dibenzosilole) derivatives. Adv. Mater. 2010, 22, E6-E27. [CrossRef] [PubMed]

16. Tang, W.; Ke, L.; Tan, L.; Lin, T.; Kietzke, T.; Chen, Z. Conjugated copolymers based on fluorine-thieno [3,2-b]thiophene for light-emitting diodes and photovoltaic cells. Macromolecules 2007, 40, 6164-6171. [CrossRef]

17. Morales, A.R.; Belfield, K.D.; Hales, J.M.; van Stryland, E.W.; Hagan, D.J. Synthesis of two-photon absorbing unsymmetrical fluorenyl-based chromophores. Chem. Mater. 2006, 18, 4972-4980. [CrossRef]

18. Cohanoschi, I.; Garcia, M.; Toro, C.; Belfield, K.D.; Hernandez, F.E. Three-photon absorption of a new series of halogenated fluorene derivatives. Chem. Phys. Lett. 2006, 430, 133-138.

19. Moore, A.; Chesney, A.; Bryce, M.; Batsanov, A.; Kelly, J.; Howard, J.; Perepichka, I.; Perepichka, D.; Meshulam, G.; Berkovic, G.; et al. Synthesis, structures and nonlinear optical properties of novel D- $\pi$-A chromophores: Intramolecular charge transfer from 1,3-dithiole of ferrocene moieties to polynitrofluorene or dicyanomethylene moieties through conjugated linkers. Eur. J. Org. Chem. 2001, 14, 2671-2687. [CrossRef]

20. Kim, H.; Cho, B. Two-photon materials with large two-photon cross sections. Structure-Property relationship. Chem. Commun. 2009, 153-164. [CrossRef] 
21. Schafer, K.; Belfield, K.; Yao, S.; Frederiksen, P.; Hales, J.; Kolattukudy, P. Fluorene-based fluorescent probes with high two-photon action cross-sections for biological multiphoton imaging applications. J. Biomed. Opt. 2005, 10, 051402. [CrossRef] [PubMed]

22. Belfield, K.D.; Schafer, K.; Liu, Y.; Liu, J.; Ren, X.; van Stryland, E. Multiphoton-absorbing organic materials for microfabrication, emerging optical applications and non-destructive three-dimensional imaging. J. Phys. Org. Chem. 2000, 13, 837-849. [CrossRef]

23. Belfield, K.; Ren, X.; van Stryland, E.; Hagan, D.; Dubikovski, V.; Meisak, E. Near-IR two photoinitiated polymerization using a fluorene/amine initiating system. J. Am. Chem. Soc. 2000, 122, 1217-1218. [CrossRef]

24. Charlot, M.; Izard, N.; Mongin, O.; Riehl, D.; Blanchard-Desce, M. Optical limiting with soluble two-photon absorbing quadrupoles: Structure-property relationships. Chem. Phys. Lett. 2006, 417, 297-302. [CrossRef]

25. Lin, T.; He, G.; Zheng, Q.; Prasad, P. Degenerate two-/three-photon absorption and optical power limiting properties in femtosecond regime of a multi-branched chromophore. J. Mater. Chem. 2006, 16, 2490-2498. [CrossRef]

26. Makarov, N.; Rebane, A.; Drobizhev, M.; Wolleb, H.; Spahni, H. Optimizing two-photon absorption for volumetric optical data storage. J. Opt. Soc. Am. B 2007, 24, 1874-1885. [CrossRef]

27. Gholami, M.; Tykwinski, R. Oligomeric and polymeric systems with a cross-conjugated $\pi$-framework. Chem. Rev. 2006, 106, 4997-5027. [CrossRef] [PubMed]

28. Hernandez, M.C.G.; Zolotukhin, M.G.; Maldonado, J.L.; Rehmann, N.; Meerholz, K.; Fröhlich, N.; Kudla, C.J.; Scherf, U. A high molecular weight aromatic PhOLED matrix polymer obtained by metal-free, superacid-catlyze polyhydroxyalkylation. Maromolecules 2009, 42, 9225-9230. [CrossRef]

29. Ricks, A.; Solomon, G.; Colvin, M.; Scott, A.; Chen, K.; Ratner, M.; Wasielewski, M. Controlling electron transfer in donor-bridge-acceptor molecules using cross-conjugated bridges. J. Am. Chem. Soc. 2010, 132, 15427-15434. [CrossRef] [PubMed]

30. Huang, F.; Tian, Y.; Chen, C.-Y.; Cheng, Y.-J.; Young, A.C.; Jen, A.K.-Y. Cross-conjugated polymers with large two-photon absorption cross-sections for metal ion sensing. J. Phys. Chem. C 2007, 111, 10673-10681. [CrossRef]

31. Aparicio-Ixta, L.; Ramos-Ortiz, G.; Pichardo-Molina, J.L.; Maldonado, J.L.; Tellez-Lopez, V.M.; Martinez-Fong, D.; Zolotukhin, M.G.; Formine, S.; Meneses-Nava, M.A.; Barbosa-Garcia, O. Two-photon excited fluorescence of silica nanoparticles loaded with a fluorene-based monomer and its cross-conjugated polymer: Their application to cell imaging. Nanoscale 2012, 4, 7751-7759. [CrossRef] [PubMed]

32. Ramos-Ortız, G.; Maldonado, J.L.; Hernandez, M.C.G.; Zolotukhin, M.G.; Fomine, S.; Fröhlich, N.; Scherf, U.; Galbrechtc, F.; Preis, E.; Salmon, M.; et al. Synthesis, characterization and third-order non-linear optical properties of novel fluorene monomers and their cross-conjugated polymers. Polymer 2010, 51, 2351-2359. [CrossRef]

33. Brabec, C.J.; Shapen, S.E.; Winder, C.W.; Sariciffci, N.S.; Denk, P. Effect of LiF/metal electrodes on the performance of plastic solar cells. Appl. Phys. Lett. 2001, 80, 1288-1290. [CrossRef]

34. StöBel, M.; Staudigel, J.; Steuber, F.; Blässing, J.; Simmerer, J.; Winnacker, A.; Neuner, H.; Metzdorf, D.; Johannes, H.; Kowalsky, W. Electron injection and transport in 8-hydroxyquinoline aluminum. Synth. Met. 2000, 111-112, 19-24.

35. Truong, Q.; Truong, M.; Park, C.; Jung, J. Study of MEH-PPV/PCBM active layer morphology and its application for hybrid solar cell performance. Bull. Mater. Sci. 2012, 35, 277-281. [CrossRef]

36. El-Daly, S.A.; Asiri, A.M.; Alamry, K.; Khan, S.A. Spectroscopic studies and laser activity of 3-(4-dimethylamino-phenyl)-1-(2,5-dimethyl-furan-3-yl)-propenone (DDFP): A new green laser dye. J. Photolum. 2013, 137, 6-14. [CrossRef]

37. El-Daly, S.A.; El-Azim, S.A.; Elmekawey, F.M.; Elbaradei, B.Y.; Shama, S.A.; Asiri, A.M. Photophysical parameters, excitation energy transfer, and photoreactivity of 1,4-bis(5-phenyl-2-oxazolyl)benzene (popop) laser dye. Int. J. Photoenergy 2012, 1-10. [CrossRef]

38. Raoufi, D.; Hosseinpanahi, F. Surface morphology dynamics in ITO thin films. J. Mod. Phys. 2012, 3, 645-651. [CrossRef]

39. Wu, H.; Huang, F.; Mo, Y.; Yang, W.; Wang, D.; Peng, J.; Cao, Y. Efficient electron Injection from a bilayer cathode consisting of aluminum and alcohol-/water-soluble conjugated polymers. Adv. Mater. 2004, 16, 1826-1830. [CrossRef] 
40. Hung, L.; Tang, C.; Mason, M. Enhanced electron injection in organic electroluminescence devices using an Al/LiF electrode. Appl. Phys. Lett. 1997, 70, 152-154. [CrossRef]

41. Szlachcic, P.; Danel, K.; Gryl, M.; Stadnicka, K.; Usatenko, Z.; Nosidlak, N.; Lewinska, G.; Sanetra, J. Organic light emitting diodes (OLED) based on helical structures containing 7-membered fused rings. Dyes Pigments 2015, 114, 184-195. [CrossRef]

42. Poloek, A.; Lin, C.; Chen, C.; Chen, C. High colour rendering index and colour stable hybrid white efficient OLEDs with a double emitting layer structure using a single phosphorescence dopant of heteroleptic platinum complexes. J. Mater. Chem. C. 2014, 2, 10343-10356. [CrossRef]

43. Gupta, B.; Kedawat, G.; Kumar, P.; Rafiee, M.; Tyagi, P.; Srivastava, R.; Ajayan, P. An n-type, new emerging luminescent polybenzodioxane polymer for application in solution-processed green emitting OLEDs. J. Mater. Chem. C. 2015, 3, 2568-2574. [CrossRef]

44. Dijken, A.; Bastiaansen, J.; Kiggen, N.; Langeveld, B.; Rothe, C.; Monkman, A.; Bach, I.; Stössel, P.; Brunner, K. Carbazole compounds host materials for triplet emitters in organic light-emitting diodes: Polymer host for high-efficiency light-emitting diodes. J. Am. Chem. Soc. 2004, 126, 7718-7727. [CrossRef] [PubMed]

45. Terada, M.; Muto, J. Concentration dependent laser threshold of rhodamine 6G in methanol solution. Opt. Comm. 1986, 59, 199-201. [CrossRef]

46. Peterson, O.; Webb, J.; McColgin, W. Organic dye threshold. J. Appl. Phys. 1971, 42, 1917-1928. [CrossRef]

47. Wiedmann, J.; Penzokofer, A. Excited-state absorption cross-sections in rhodamine dyes determined after molecular reorientation. Il Nuovo Cimento 1981, 63B, 459-469. [CrossRef]

48. Penzokofer, A.; Leupacher, W. Fluorescence behavior of highly concentrated Rhodamine 6G solutions. J. Lumin. 1987, 37, 61-72. [CrossRef]

49. Pauck, T.; Hennig, R.; Perner, M.; Lemmer, U.; Siegner, U.; Mahrt, R.F.; Scherf, U.; Müllen, K.; Bässler, H.E.; Göbel, O. Femtosecond dynamics of stimulated emission and photoinduced absorption in a PPP-type ladder polymer. Chem. Phys. Lett. 1995, 244, 171-176. [CrossRef]

50. Yan, M.; Rothberg, L.J.; Kworck, E.W.; Miller, T.M. Interchain excitations in conjugated polymers. Phys. Rev. Lett. 1995, 75, 1992-1995. [CrossRef] [PubMed]

51. Rothberg, L.J.; Yan, M.; Ppdimitrakopoulos, F.; Galvin, M.E.; Kworck, E.W.; Miller, T.M. Photophysics of phenylenevinylene polymers. Synth. Met. 1996, 80, 41-58. [CrossRef]

52. Hide, F.; Diaz-García, M.A.; Schwartz, B.J.; Andersson, M.R.; Pei, Q.; Heeger, A.J. Semiconducting polymers: A new class of solid-state laser materials. Science 1996, 273, 1833. [CrossRef] 